\title{
Factors from fluid of the ovarian pocket that stimulate sperm motility in domestic hens
}

\author{
K. Ashizawa ${ }^{1}$ and G. J. Wishart ${ }^{2}$ \\ ${ }^{1}$ Laboratory of Animal Reproduction, Faculty of Agriculture, Miyazaki University, \\ Miyazaki 889-21, Japan; and ${ }^{2}$ Department of Molecular and Life Sciences, Dundee Institute of \\ Technology, Bell Street, Dundee DDI $1 H G, U K$
}

\begin{abstract}
Summary. Fluid was collected from the region of the peritoneum surrounding the ovarian pocket of domestic hens at about the time of ovulation. This fluid, diluted to $10 \%$, increased the motility of chicken spermatozoa by a maximum of sixfold at $40^{\circ} \mathrm{C}$ in vitro. Gel filtration revealed two peaks of motility-stimulating activity: one was identified as calcium and the other as a heat-labile substance of low $M_{\mathrm{r}}(200)$. It is suggested that this motility-stimulating activity may facilitate fertilization, as spermatozoa are normally stored in a quiescent state within the oviduct and can be passively transported by cilia to the site of fertilization in the ovarian pocket.
\end{abstract}

Kelwords: spermatozoa: motility; domestic hen; fertilization

\section{Introduction}

Munro (1938) first suggested that avian spermatozoa may be immotile during most of their sojourn in the female reproductive tract. He noted that chicken spermatozoa remained immotile in vitro when suspended in a simple salt solution at the avian body temperature of $40-41^{\circ} \mathrm{C}$. This view is supported by the observation that in the uterovaginal sperm storage tubules, where avian spermatozoa may remain for several weeks before fertilization (see Lake, 1975), spermatozoa appear to be mostly immotile (Bakst, 1987). In addition, sperm motility does not seem to be required in domestic hens for the movement of spermatozoa within the oviduct from the shell gland (uterus) to the magnum, as dead spermatozoa on inert particles, such as carbon powder, inserted in the shell gland are transported along the reproductive tract (Mimura, 1939, 1941). However, it has been shown that only motile spermatozoa can transverse from the posterior to the anterior vagina (Takeda, 1974) and it has been suggested that factors within seminal plasma, deposited with the spermatozoa, may enhance intravaginal sperm transport (Terada et al., 1984). Two factors that stimulate sperm motility, calcium and an unidentified regulator of low $M_{\mathrm{r}}$, have been identified in seminal plasma of chickens (Ashizawa \& Wishart, 1987).

The penetration of an ovum by avian spermatozoa involves hydrolysis of the proteinaceous perivitelline layer by sperm acrosomal enzymes (Bakst \& Howarth, 1977; Okamura \& Nishiyama, 1978). In some mammalian species, development of hyperactivated sperm motility is associated with capacitation and is considered important for penetration of the zona pellucida (Yanagimachi, 1981). As penetration of the avian perivitelline layer appears to occur in an analogous manner to penetration of the zona pellucida, it is possible that chicken spermatozoa must also be motile to locate and penetrate the perivitelline layer. Furthermore, as these spermatozoa will have previously been immotile within the sperm-storage tubules (see Bakst, 1987), their motility will need to be stimulated by factors associated with the ovum or its surrounding fluids.

At the time of ovulation, fluid collects inside the ovarian pocket (P. E. Lake, pers. commun.) which is the portion of the body cavity immediately adjacent to the ovary and the infundibulum. 
The ovarian pocket is enclosed by the body wall, the left abdominal air sac and the viscera (see Olsen \& Nehrer, 1948). Fertilization occurs within this part of the peritoneum either before, or within 15-20 min of, entry of the ovulated ovum into the infundibulum (Warren \& Scott, 1934; Olsen \& Nehrer, 1948; Okamura \& Nishiyama, 1978). After this, the outer perivitelline layer is laid down (Bain \& Hall, 1969) and is impenetrable to spermatozoa (Bakst \& Howarth, 1977). Since spermatozoa are found in ovarian pocket fluid taken at the time of ovulation (Bobr et al., 1964) and since the infundibulum actively engulfs the ovulated ovum, or even surrounds the preovulatory follicle at this time (Warren \& Scott, 1934; Phillips \& Warren, 1937), it may be presumed that this fluid represents the milieu in which fertilization takes place. We examined the ability of this fluid to stimulate sperm motility and attempted to separate and identify the factors involved.

\section{Materials and Methods}

\section{Animals}

Male domestic chickens were a Rhode Island Red-type control strain (from Ross Poultry Ltd, Newbridge, Midlothian, UK) and hens were a commercial laying strain (Hi-Sex, Euribrid). All birds were caged individually, given I 4:00 h light: 10:00 h dark and fed a proprietary breeders' ration ad libitum.

\section{Collection and treatment of ovarian pocket fluid}

Hens were killed by cervical dislocation 15-20 min after oviposition and laparotomized. The viscera were carefully drawn aside to reveal the 5-10 ml of fluid lying within the region of the ovarian pocket, and this fluid was removed with a pipette. Only straw-coloured fluid was retained; blood-contaminated samples were discarded. The fluid was then centrifuged at $105000 \mathrm{~g}$ for $1 \mathrm{~h}$ at $5^{\circ} \mathrm{C}$. The supernatant was stored at $-20^{\circ} \mathrm{C}$ directly, or after concentrating it tenfold by freeze drying. Calcium was removed from the fluid with Dowex $50 \times 4-200$ as described by Ashizawa \& Wishart (1987). The resin was converted to the sodium form with $1 \mathrm{~mol} \mathrm{NaOH} 1^{-1}$ and then washed and equilibrated with $\mathrm{NaCl}$-TES buffer $\left(0 \cdot 15 \mathrm{~mol} \mathrm{NaCl} 1^{-1}\right.$ with $20 \mathrm{mmol}$ TES ( $N$-[hydroxymethyl]methyl-2-aminoethanesulfonic acid) $\mathrm{I}^{-1}$ adjusted to $\mathrm{pH} 7.4$ with $\left.1 \mathrm{~mol} \mathrm{NaOH} 1^{-1}\right)$. This was then mixed well with the samples at $20 \%(\mathrm{w} / \mathrm{v})$ to remove calcium. Characterization of the sperm motility-stimulating factors was achieved by further treating fluid from ovarian pockets by immersion in a bath of boiling water for $5 \mathrm{~min}$ and by organic extraction, by mixing with 5 volumes of chloroform.

\section{Gel filtration}

Sephadex G-15-120 (Pharmacia Fine Chemicals, Inc, UK) was hydrated and equilibrated with NaCl-TES buffer in a $1.8 \times 100 \mathrm{~cm}$ column: $1 \mathrm{ml}$ of concentrated $(\times 10)$ ovarian pocket fluid was passed through the column at $80 \mathrm{ml}$ $\mathrm{h}^{-1}$ at $5^{\circ} \mathrm{C}$ and $80 \times 5 \mathrm{ml}$ samples were collected and stored at $5^{\circ} \mathrm{C}$ before assay.

\section{Preparation of spermatozoa}

Samples of semen pooled from four to six males were diluted eightfold with $\mathrm{NaCl}$-TES buffer at room temperature, mixed and centrifuged at $700 \mathrm{~g}$ for $12 \mathrm{~min}$. The pellet of spermatozoa was reconstituted gently in the same buffer to give a concentration of about $1 \times 10^{9}$ spermatozoa $\mathrm{ml}^{-1}$. These preparations were incubated in $4 \mathrm{ml}$ quantities in $25 \mathrm{ml}$ Nalgene flasks in a shaking water bath at $40 \mathrm{C}$.

\footnotetext{
Assays

Sperm motility was assayed spectrophotometrically and was defined by the parameter $\%(\Delta O D) \mathrm{m}$, which represents the maximum proportional decrease in optical density at $550 \mathrm{~nm}$ occurring after the movement of a suspension of spermatozoa through a flow cell is arrested, and correlates with the percentage of motile spermatozoa. The constant ODm, whch represents the maximum optical density obtained as a suspension of spermatozoa is drawn through a flow cell, was used to estimate concentrations of spermatozoa (Wishart \& Ross, 1985). All parameters were measured 15-20 s after exposure of spermatozoa to a given medium. Calcium was measured spectrophotometrically with the indicator Arsenazo 111 (Gratzer \& Beaven, 1977) and protein concentration was measured with Folin's reagent (Lowry et al., 1951). Concentrations of adenosine triphosphate (ATP) in spermatozoa were measured in boiled extracts using firefly extract luminescence as described by Wishart (1982). Osmotic pressure was measured by freezing-point depression with an Advanced Digimatic Osmometer (Advanced Instruments Inc., Needham Heights, MA, USA).
} 


\section{Statistical analysis}

Data were subjected to analyses using Student's $t$ test. All given estimations are shown as means $\underline{\mathrm{SEM}}$.

\section{Results}

Increasing concentrations of native or calcium-depleted fluid from the ovarian pocket stimulated motility of chicken spermatozoa (Fig. 1a). In the presence or absence of calcium, the relationship between the concentration of ovarian pocket fluid and spermatozoa motility was hyperbolic as shown by the linear nature of the reciprocal plot (Fig. 1b). This plot shows that calcium accounts for about $70 \%$ of the motility-stimulating activity of the fluid from the ovarian pocket. The concentration of free calcium in ovarian pocket fluid was $2 \cdot 04 \pm 0.14 \mathrm{mmol}^{-1}(n=5)$ and was negligible in the Dowex-treated fluid. Maximum stimulation of motility was achieved with $8 \%$ fluid. Further increases in motility with higher fluid concentration were not limited by energy availability: samples
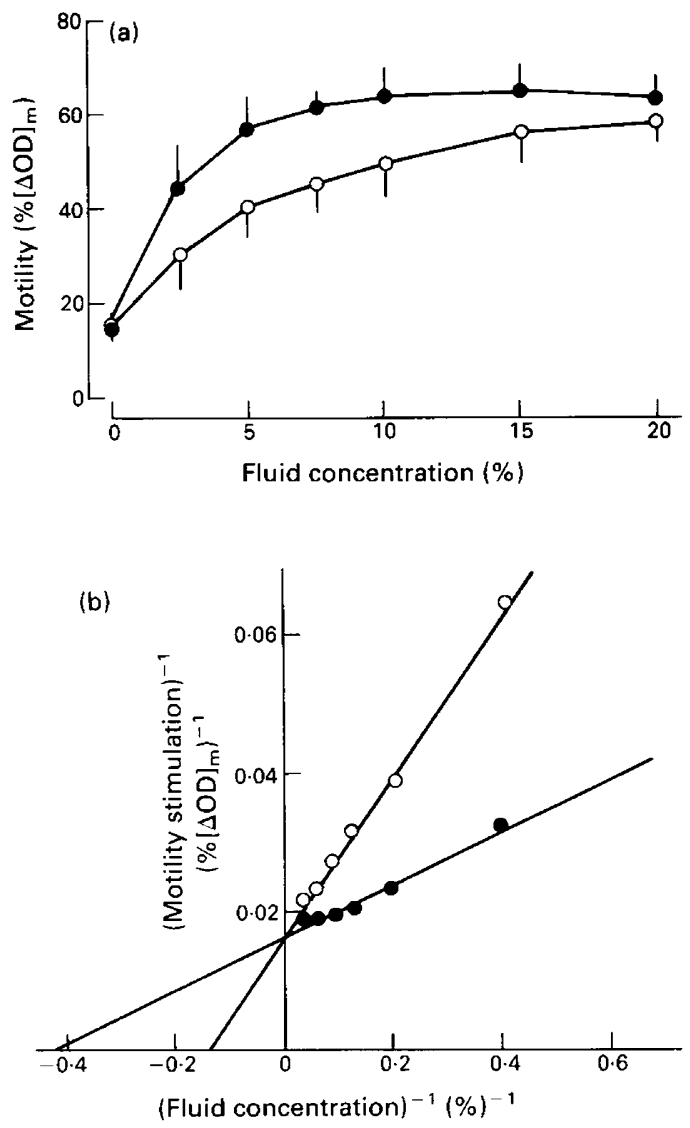

Fig. 1. Potency of motility-stimulating activity of hen ovarian-pocket fluid before ( $)$ and after (O) Dowex treatment to remove calcium. (a) Each point represents the mean \pm SEM of motility of three samples of spermatozoa after exposure for $20 \mathrm{~s}$ to differing concentrations of different fluid samples, before and after Dowex treatment; (b) reciprocal plot of mean estimations from the same data. The parameter $\%(\Delta O D) m$ represents the maximum proportional decrease in optical density at $550 \mathrm{~nm}$ occurring after the movement of a suspension of spermatozoa through a flow cell is arrested, and correlates with the percentage of motile spermatozoa. 


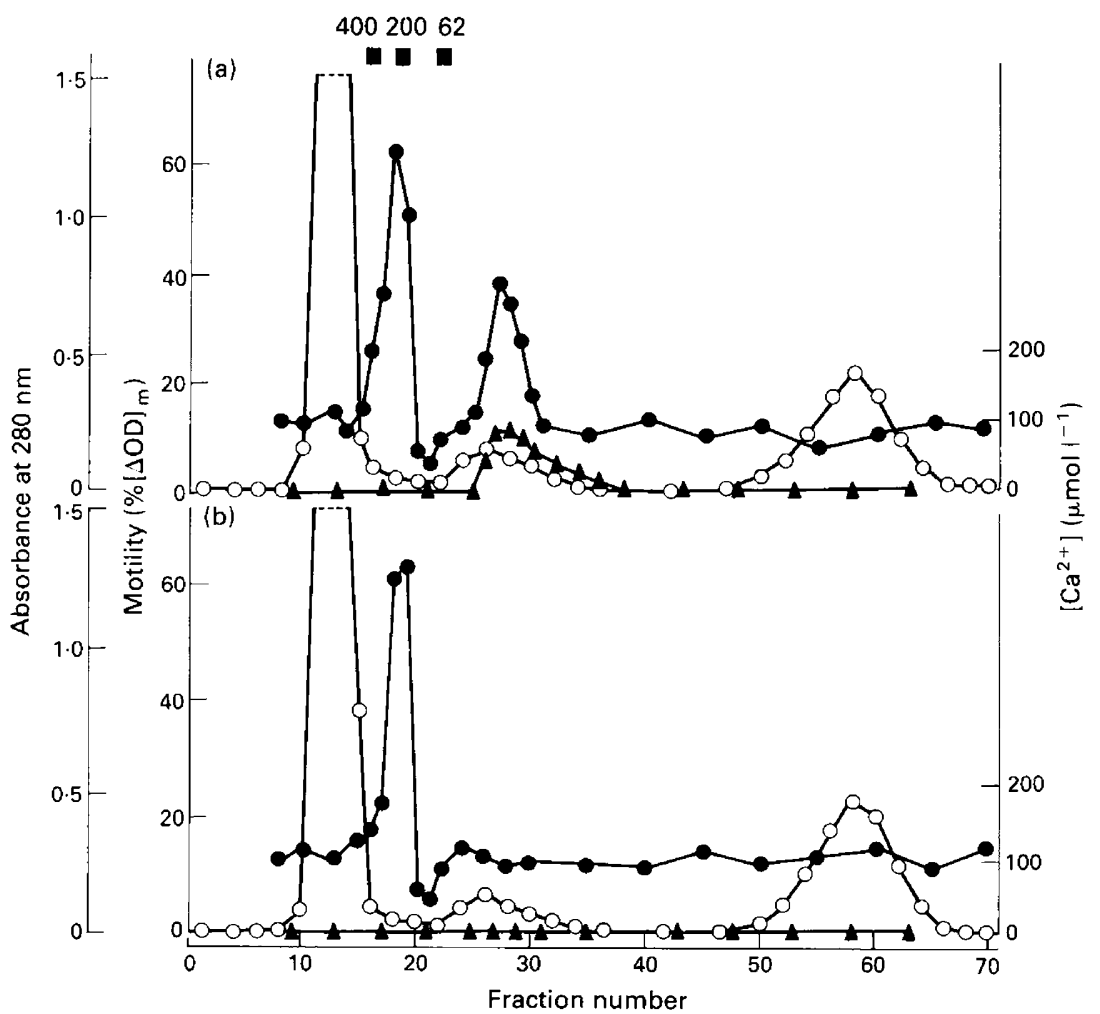

Fig. 2. Separation of motility-stimulating activities of fowl hen ovarian-pocket fluid using Sephadex G-15-120. The elution profiles represent fractions from the same sample (a) before and (b) after Dowex treatment to remove calcium. Calcium concentrations $(\boldsymbol{\Delta})$ and absorbance at $280 \mathrm{~nm}(O)$ of samples are shown with motility-stimulating activity $(\bullet)$ measured as the motility of a standard sample of spermatozoa suspended in a portion of each fraction. The $M_{\mathrm{r}}$ 'markers' ( $\left.\mathbf{\square}\right)$ were ethanediol $\left(\mathrm{M}_{\mathrm{r}} 62\right)$ and polyethylene glycol $\left(M_{\mathrm{r}} 200\right.$ and 400$)$. The parameter $\%(\triangle \mathrm{OD}) \mathrm{m}$ represents the maximum proportional decrease in optical density at $550 \mathrm{~nm}$ occurring after the movement of a suspension of spermatozoa through a flow cell is arrested, and correlates with the percentage of motile spermatozoa.

of spermatozoa in the presence and absence of $10 \%$ peritoneal fluid had ATP concentrations which, at $40.3 \pm 2.4$ and $38.4 \pm 1 \cdot 1 \mathrm{nmol}$ per $10^{9}$ spermatozoa, respectively $(n=3)$, were not significantly different $(P>0 \cdot 01)$.

Gel filtration of the native fluid revealed two peaks of motility-stimulating activity, with peaks in fractions 18 and 27 (Fig. 2a). The effectiveness and specificity of calcium removal were evident (Fig. 2b); both calcium and the second peak of motility-stimulating activity disappeared, whereas the characteristic pattern of the other parameters remained unchanged.

In both native and Dowex-treated samples, osmolality was greatest in fractions 21 , at 441 and $481 \mathrm{mosmol} \mathrm{kg}{ }^{-1}$, respectively, against a background buffer osmolality of $310-315 \mathrm{mosmol} \mathrm{kg}^{-1}$. The peak of $A_{280}$ in fractions 11-14 was confirmed to be protein, by the method of Lowry et al. (1951). Fractions $57-61$, which also had a high $A_{280}$, did not contain protein. The motilitystimulating activity of $10 \%$ ovarian pocket fluid treated with Dowex was significantly $(P<0.01)$ reduced from $49.3 \pm 5.8$ to $15.7 \pm 0.6$ by boiling for $5 \mathrm{~min}$, whereas boiling had no significant $(P>0.01)$ effect on the motility-stimulating activity of native fluid, although changing it from $68.8 \pm 4.4$ to $55.5 \pm 6.7 \%(\Delta \mathrm{OD}) \mathrm{m}$ units $(n=3)$. Extraction with chloroform also had no significant $(P>0.01)$ effect on the motility-stimulating activity of native $(68.8 \pm 4.4$ versus $65.7 \pm 3.6)$ 
and of Dowex-treated $(49 \cdot 3 \pm 5 \cdot 8$ versus $37.8 \pm 2 \cdot 9)$ fluid (parameters as above). Sperm motility measured after $5 \mathrm{~min}$ exposure to $10 \%$ Dowex-treated fluid at $40^{\circ} \mathrm{C}$ was significantly $(P<0.01)$ reduced with respect to motility measured after $15-20$ s exposure $(30 \cdot 7 \pm 4 \cdot 4$ versus $17 \cdot 1 \pm 2 \cdot 7)$. With $10 \%$ native fluid, motility after 5 min exposure was not significantly different $(P>0.01)$ from that measured after $15-20$ s exposure $(40 \cdot 5 \pm 2 \cdot 5$ versus $40 \cdot 9 \pm 2 \cdot 3 ; n=5)$.

\section{Discussion}

The results show that the fluid that collects in the ovarian pocket at the time of ovulation contains two sperm motility-stimulating factors: one was identified as calcium and the other, which remains unidentified, is a substance of $M_{\mathrm{r}}$ about 200 which is heat labile and not extractable with organic solvents. The position of this factor within the fractions obtained from the Sephadex G-15-120 column is analogous to that of the motility-stimulating factor identified in chicken seminal plasma (Ashizawa \& Wishart, 1987) and may be the same substance. Apart from calcium, two other low molecular weight factors have been shown to stimulate fowl sperm motility: caffeine (Wishart \& Ashizawa, 1987) and bicarbonate (Ashizawa et al., 1989). The stimulating effect of the unknown factor was transient, lasting less than $5 \mathrm{~min}$. Thus its mode of action may be similar to that of caffeine, which also stimulates a transient response, rather than that of calcium or bicarbonate, which invoke a more sustained increase in sperm motility.

The source of this ovulation-associated, ovarian pocket fluid is not known. It is unlikely to have originated from the ovary since follicular fluid is not present in the follicles of laying hens and the follicular blood supply appears to be reduced at the time of ovulation (Phillips \& Warren 1937). Although the fluid may be partly peritoneal in origin, another potential source is the oviduct. In many mammalian species, oviductal fluids flow into the peritoneal cavity, the greatest production occurring at the time of ovulation (see Hamner, 1973). In domestic hens, at the time of ovulation, the infundibulum becomes oedematous and extremely active, particularly in the ovarian pocket adjacent to the mature follicle (Warren \& Scott, 1934; Phillips \& Warren, 1937) and its fluid volume is maximum (Morzenti et al., 1978). Furthermore, spermatozoa are most numerous within the infundibular (Morzenti et al., 1978) and ovarian pocket (Bobr et al., 1964) fluids at this time.

El Jack \& Lake (1967) suggested that uterine fluids might contain sperm-motility-stimulating factors that could influence sperm movement within the reproductive tract in hens and Brillard et al. (1987) showed that uterine fluids stimulated motility of chicken spermatozoa in vitro. However the 'plumping' and 'oviposition' fluids from the uterus contained, respectively, seven and 12 times more calcium (El Jack \& Lake, 1967) than the ovarian fluid, so direct transfer of the uterine fluid to the infundibulum and peritoneum seems unlikely.

Whatever the source of this fluid, evidence suggests that it is the fluid that surrounds the ovum at the time of fertilization and that the sperm motility-stimulating factors may be implicated in promoting fertilization in domestic hens.

We thank the Japanese Ministry of Education, Science and Culture (No. 0156022294) (K. Ashizawa) and the Agricultural and Food Research Council, UK (G. Wishart) for support. Part of this work was carried out by both authors at the AFRC Poultry Research Centre.

\section{References}

Ashizawa, K. \& Wishart, G.J. (1987) Resolution of the sperm motility-stimulating principle of fowl seminal plasma into $\mathrm{Ca}^{2+}$ and an unidentified low molecular weight factor. Journal of Reproduction and Fertility 81, 495-499.
Ashizawa, K., Masazumi, S. \& Okauchi, K. (1989) Stimulation of the motility and oxygen consumption of fowl spermatozoa by bicarbonate at $40^{\circ} \mathrm{C}$. Animal Reproduction Science 21, 301-308. 
Bain, J.M. \& Hall, J. (1969) Observations on the development and structure of the vitelline membrane of the hens egg: an electron microscope study. Australian Journal of Biological Sciences 22, 653-665.

Bakst, M.R. (1987) Anatomical basis of sperm-storage in the avian oviduct. Scanning Microscopy 1 , $1257-1266$.

Bakst, M.R. \& Howarth, B., Jr (1977) Hydrolysis of the hen's perivitelline layer by cock sperm in vitro. Biology of Reproduction 17, 370-379.

Bobr, L.W., Ogasawara, F.X. \& Lorenz, F.W. (1964) Distribution of spermatozoa in the oviduct and fertility in domestic birds, II. Transport of spermatozoa in the fowl oviduct. Journal of Reproduction and Fertility 8, 49-58.

Brillard, J.P., Galut, O. \& Nys, Y. (1987) Possible causes of subfertility in hens following insemination near the time of oviposition. British Poultry Science 28, 307318 .

El Jack, M.H. \& Lake, P.E. (1967) The content of the principal inorganic ions and carbon dioxide in uterine fluids of the domestic hen. Journal of Reproduction and Fertility 13, 127-132.

Gratzer, W.B. \& Beaven, G.H. (1977) Use of the metal-ion indicator, Arsenazo 111, in the measurement of calcium binding. Analytical Biochemistry 81, $118-129$.

Hamner, C.E. (1973) Oviducal fluid-composition and physiology. In Handbook of Physiology, Vol. 2: Female Reproductive Systems, Part 2, pp. 141-151. Eds R. O. Greap \& E. B. Astwood. American Physiological Society, Washington.

Lake, P.E. (1975) Gamete production and the fertile period with particular reference to domesticated birds. Symposium of Zoological Society of London 35, 225-244.

Lowry, O.H., Rosebrough, N.J., Farr, A.L. \& Randall, R.J.D. (1951) Protein measurement with the Folin phenol reagent. Journal of Biological Chemistry 193, 265275 .

Mimura, H. (1939) On the mechanism of travel of spermatozoa through the oviduct in the domestic fowl, with special reference to artificial insemination. Okajimas Folia Anatomica Japonica 17, 459-476.

Mimura, H. (194l) Studies on the mechanism of travel of spermatozoa through the oviduct in the domestic fowl. Journal of Department of Agriculture of Kyushu Imperial University 6, 167-259.

Morzenti, A., Ogasawara, F.X. \& Fuqua, C.L. (1978) The relationship of infundibular fluid to the avian sperm transport mechanisms. Poultry Science 57, 1173.

Munro, S.S. (1938) Fowl sperm immobilisation by a temperature-media interaction and its biological signficance. Quarterly Journal of Experimental Physiology 27, 281291.

Okamura, F. \& Nishiyama, H. (1978) The passage of spermatozoa through the vitelline membrane in the domestic fowl, Gallus gallus. Cell and Tissue Research 188, 497-508.

Olsen, M.W. \& Nehrer, B.H. (1948) The site of fertilization in the domestic fowl. Journal of Experimental Zoology 109, 355-366.

Phillips, R.E. \& Warren, D.C. (1937) Observations concerning the mechanics of ovulation in the fowl. Journal of Experimental Zoology 76, 117-136.

Takeda, A. (1974) The transport of spermatozoa in the vagina of the hen. Japanese Poultry Science 11, 45-54.

Terada, T., Watanabe, M. \& Tsutsumi, Y. (1984) Possible significance of accessory reproductive fluid in the exhibition of fertilizing ability of spermatozoa in the domestic fowl. Japanese Journal of Zootechnical Science 55, 52-58.

Warren, D.C. \& Scott, H.M. (1934) Ovulation in the domestic hen. Science 80, 461-462.

Wishart, G.J. (1982) Maintenance of ATP concentrations in and of fertilizing ability of fowl and turkey spermatozoa in vitro. Journal of Reproduction and Ferility 66, 457-462.

Wishart, G.J. \& Ashizawa, K. (1987) Regulation of the motility of fowl spermatozoa by calcium and cAMP. Journal of Reproduction and Fertility 80, 607-611.

Wishart, G.J. \& Ross, F.H. (1985) Characterisation of a spectrophotometric technique for the estimation of fowl and turkey sperm motility. Gamete Research 11, 169. 178.

Yanagimachi, R. (1981) Mechanisms of fertilization in mammals. In Fertilization and Embryonic Development in vitro, pp. 81-182. Eds L. Mastroianni \& D. J. Biggers, Plenum Press, New York.

Revised version received 4 July 1991 